\title{
Upper Gastro Instestinal Endoscopic Findings In Patients With Dyspepsia: Our Experience At Cims, Bilaspur, Chhattisgarh, India
}

\author{
Yasmeen Khan ${ }^{1}$, S.K. Mohanty ${ }^{2}$ Hemant Kumar ${ }^{3}$ Sachin Pandey ${ }^{4}$ \\ ${ }^{1}$ Associate professor,Department of Medicine, ${ }^{2}$ Dean and Professor, Department of Surgery, \\ ${ }^{3}$ Professor Department of Pediatrics, ${ }^{4}$ Assistant Professor, Department of PSM. Chhattisgarh Institute Medical \\ Sciences, Bilaspur, Chhattisgarh, India
}

\begin{abstract}
:
Objective:Aim of the study was to evaluate Upper Gastro Intestinal endoscopic findings in patients presenting with dyspepsia and to campare with earlier studies.

Material and Method:This retrospective, observational study was conducted in endoscopic unit in the Department of Medicine in chhattisgarh institute of medical sciences, fromJuly 2007 to December 2011. Adult patients with dyspepsia who underwent Upper Gastro Intestinal endoscopies where included in the studies. Patients were referred by the consultants and doctors working in the periphery for endoscopy. Endoscopies were performed as per standard protocol with diagnoses based on accepted criteria.

Results: Upper Gastro Intestinal endoscopies were performed on a total of 593 patients. Patients who presented with dyspepsia were scoped. Amongst them $64.9 \%(n=385)$ were male and $35.1 \%(n=208)$ were females. The mean age of the studied population was 41.45 years $\left(S D^{+}-15.343\right)$, most common lesion was gastritis seen in $25.1 \%(n=149)$, esophagitis $3.5 \%(n=21)$, gastric carcinoma $4.6 \%(n=27)$, esophageal carcinoma $3.7 \%$ $(n=22)$, gastric ulcer $6.7 \%(n=40)$ duodenal ulcer was found in $4 \%(n=24)$. Gastric ulcer was more common as compared to duodenal ulcer (6.7\% vs. 4\%).Endoscopy was normal in $40.0 \%(n=237)$ of the patients.

Conclusion: Endoscopy is a very important investigative modality to identify the specific pathology in patients of dyspepsia .Gastritis; Esophagitis, Duodenitis, Duodenal ulcer,Gastric ulcer, Gastric carcinomas and esophageal carcinoma were the commonest endoscopic diagnostic findings.
\end{abstract}

Keywords: Esophagogastroduodenoscopy, dyspepsia

\section{Introduction}

Upper Gastro Intestinal endoscopy is the most sensitive investigation for diagnosing upper GI diseases. Majority of the patients referred for endoscopy have symptoms termed as dyspepsia [1,2,3]. Dyspepsia refers to pain or discomfort in epigastrium. The aim of our study was to identify the spectrum of diseases found on upper GI endoscopies in patients presenting with dyspepsia and to campare with earlier studies.Dyspepsia has an extensive differential diagnosis and heterogeneouspathophysiology. It is responsible for substantial health costs and considerable time loss from work. It may be an early symptom of a serious disease or it may be just functional. The endoscopy was performed by one of the authors ${ }^{1}$ and the study has approval of the college authority. Statistical analysis was done by SPSS (11.5 versions).

Cross Tab Table 1a Endoscopic Diagnosis Patients And Their Gender Distribution

\begin{tabular}{|c|c|c|c|c|}
\hline \multirow[b]{2}{*}{ Diagnosis } & & \multicolumn{2}{|c|}{ SEX } & \multirow[b]{2}{*}{ Total } \\
\hline & & Male & Female & \\
\hline Esophagitis & $\begin{array}{l}\text { Count } \\
\% \text { of Total }\end{array}$ & $\begin{array}{l}12 \\
2.0 \%\end{array}$ & $\begin{array}{l}9 \\
1.5 \%\end{array}$ & $\begin{array}{l}21 \\
3.5 \%\end{array}$ \\
\hline \multirow{2}{*}{$\begin{array}{l}\text { Esophageal } \\
\text { Candidiasis }\end{array}$} & Count & 3 & 5 & 8 \\
\hline & $\%$ of Total & $.5 \%$ & $.8 \%$ & $1.3 \%$ \\
\hline Esophageal Varices & Count & & & \\
\hline \multirow{2}{*}{ Gastritis } & $\begin{array}{l}\text { Count } \\
\text { Coul }\end{array}$ & $\begin{array}{l}1.2 \% \\
105\end{array}$ & $.2 \%$ & $\begin{array}{l}1.3 \% \\
149\end{array}$ \\
\hline & $\%$ of Total & $17.7 \%$ & $7.4 \%$ & $25.1 \%$ \\
\hline \multirow[t]{2}{*}{ Gastric Ulcer } & Count & 15 & 25 & 40 \\
\hline & $\%$ of Total & $2.5 \%$ & $4.2 \%$ & $6.7 \%$ \\
\hline \multirow[t]{2}{*}{ Duodenitis } & Count & 18 & 12 & 30 \\
\hline & $\%$ of Total & $3.0 \%$ & $2.0 \%$ & $5.1 \%$ \\
\hline
\end{tabular}




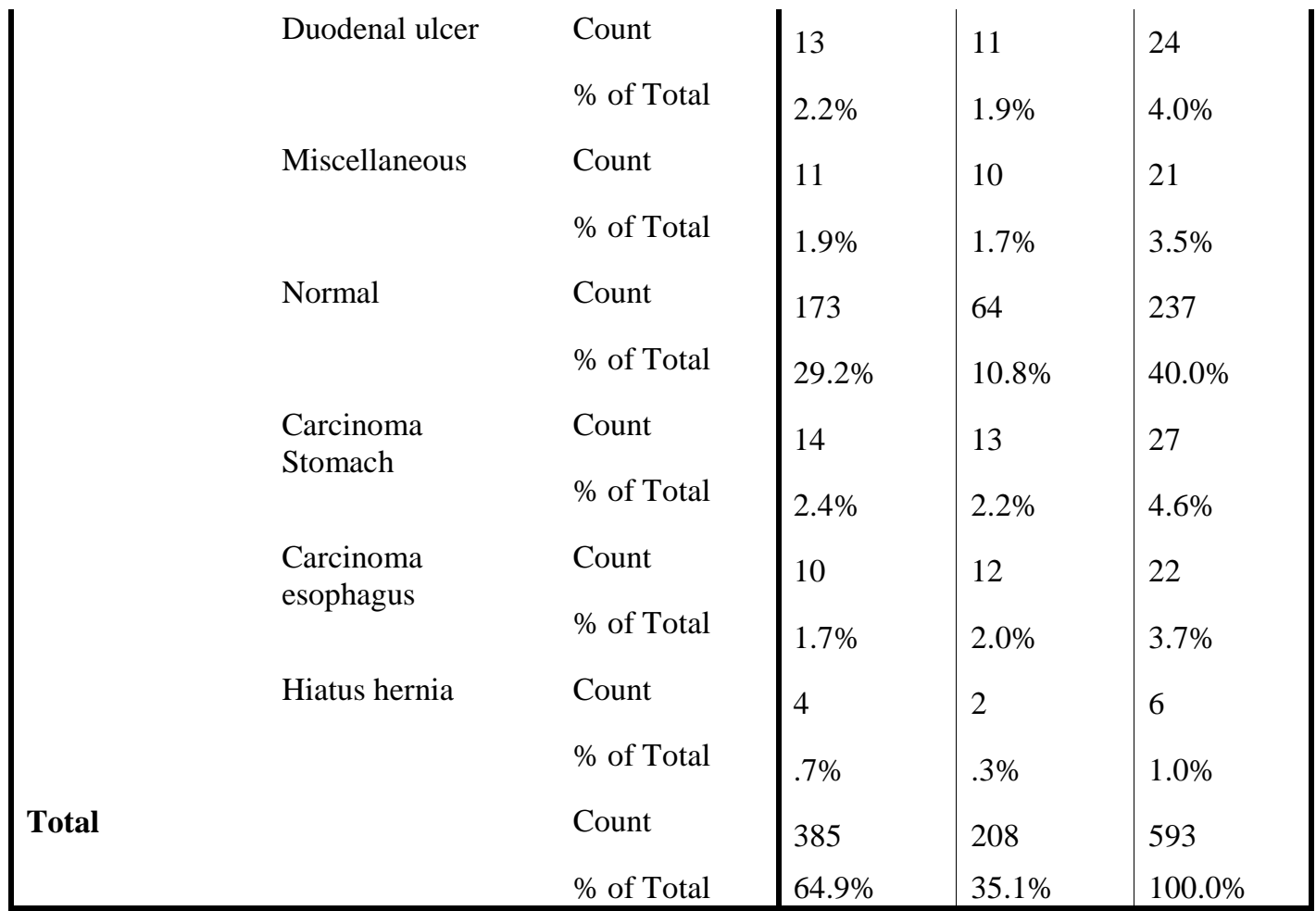

Table 1B:- Pie Diagram of diagnosis of all Patients

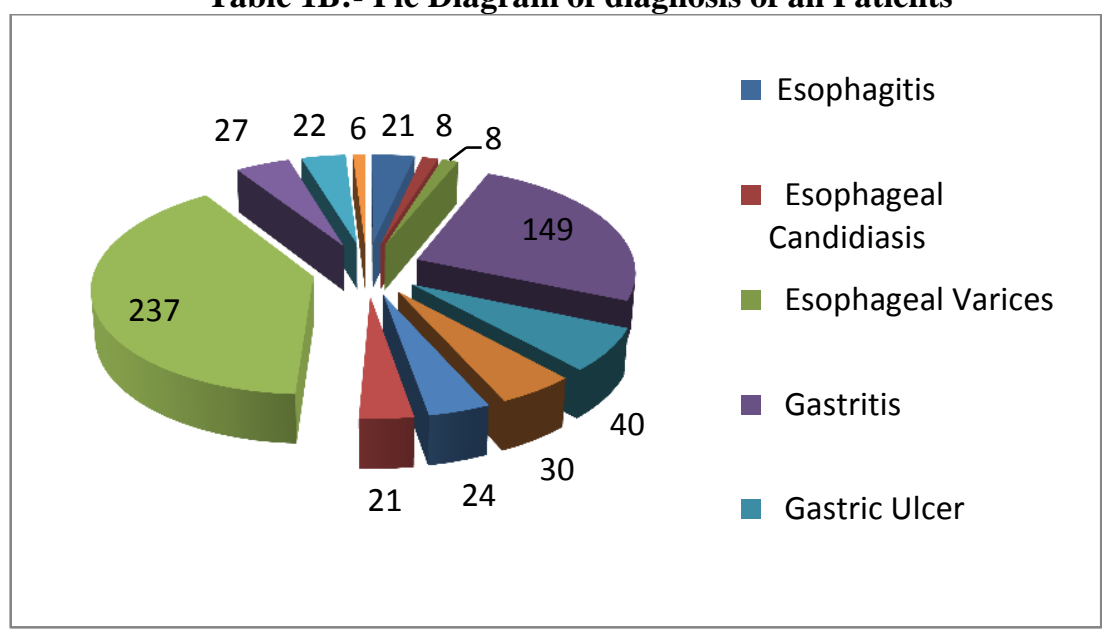

II. Material And Methods

This is a retrospective,observational study conducted in the Endoscopic unit of the Department of Medicine, CIMS, Bilaspur, and Chhattisgarh, from July 2007 to Dec 2011 .Adult patients who underwent endoscopies were patients received from all departments and including both urban and rural peripheral areas. They were either referred from outpatient department, private clinics (open access ) or were admitted patients (booked cases).Endoscopies were performed in the standard way using Olympus Video Endoscopy[4].

Our study included adult patients (aged between 20-80 years with dyspepsia)the patients record included name, age sex,address, habits and indication for OGD .Procedures were performed and endoscopy findings were documented. Histo-pathological reports were acknowledged. Helicobacter pylori status was available for few cases only .We excluded patients positive for Hepatitis $\mathrm{B}$ and $\mathrm{C}$ infection. 
Table 2: Bar diagram between Age Interval with Gender wise

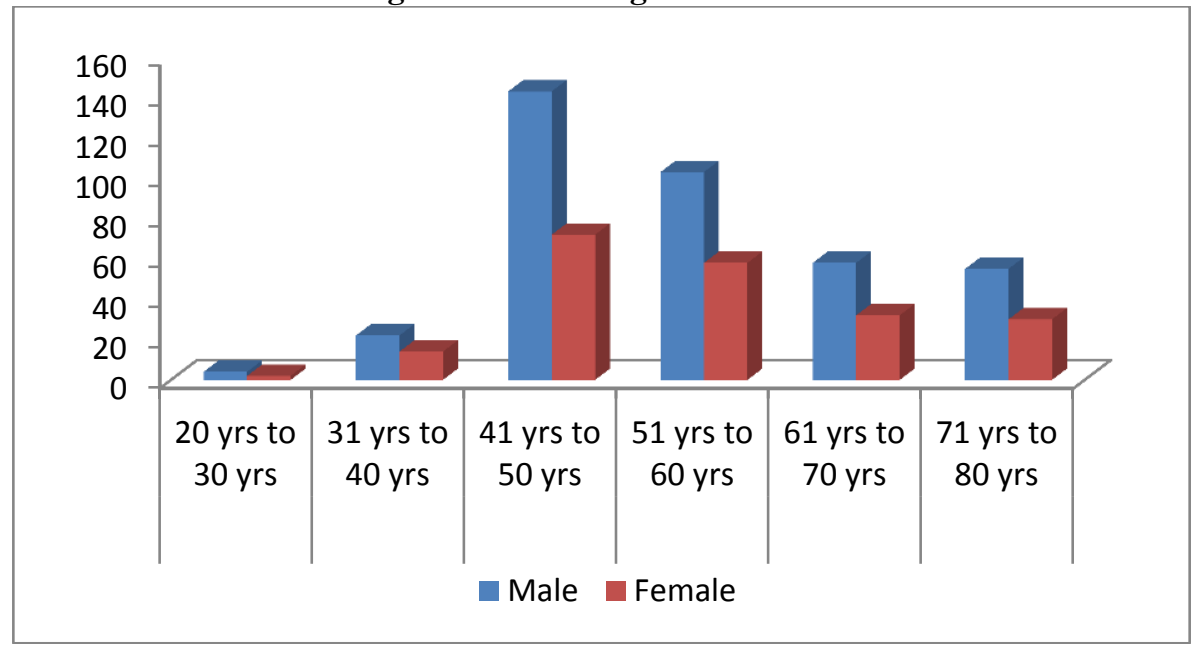

\section{Results}

Upper GI Endoscopy was performed on 593 patients of dyspepsia. No significant complications were recorded except for one patient who had syncope, and was resuscitated. No patient died during the procedure .The age of the patients ranged between 20-80 years with a mean age of 41.5years ( $\mathrm{SD} \pm 15.34)$.Majority of the patients who underwent the procedure were in the fifth decade of their lives,. males were $64.9 \%(\mathrm{n}=385)$ and females $5.1 \%(\mathrm{n}=208)$.Males were more as compared to females (Table no.2) Single endoscopic diagnosis was made in $61 \%$.Most of the patients had multiple pathology and was seen in $3.05 \%(\mathrm{n}=18)$.Gastritis, Duodenitis ,DU were seen in various combinations Miscellaneous lesions were reported in 3.5\% $(n=21)$. The lesions included Achalasia, Diffuse esophageal spasm. Barrett's esophagus,foreign bodies, duodenal polyp. Abnormal OGD were more common in patients of older age group compared to younger age group. Esophagitis $35 \%(\mathrm{n}=21)$, Esophageal candidiases $13 \%(\mathrm{n}=8)$, Esophageal varices $13 \%(\mathrm{n}=8)$, Gastritis $25 \%(\mathrm{n}=149)$, Gastric ulcer $6.7 \%(\mathrm{n}=40)$ Duodenitis 5.1\% $(\mathrm{n}=30)$, Duodenal ulcer $4 \%(\mathrm{n}=24)$, carcinoma stomach $46 \%(\mathrm{n}=27)$, Carcinoma esophagus $3.7 \%(\mathrm{n}=22)$. (Table1A, 1B) .There were more males $27.2 \%(\mathrm{n}=173)$ as compared to females $10.8 \%(n=64)$.

Correlations of Endoscopic diagnosis and with their personal habits as obtained $\mathrm{r}=.160(\mathrm{p}=.000<.001)$ which is highly significant (Table no 4).

\section{Discussion}

In this study ,there were more males $64.9 \%$ than females $35.1 \%$; ratio is $1.8: 1$ similar to findings in majority of other countries ,probably because UGI tract diseases are more prevalent in males $[5,6,7,8,9]$.Olokaba et al ,llorm noticed a male to female ratio of 1.05[5]. More male to female ratio was also reported by Adulful et al in Accra, Ghana and similar studies of AgbaKwuru et al,,Danbanauch et al, in Zaria ,North West Nigeria . Emmanuel jeje et al, also reported more male preponderance. A study conducted at Multan by Muhammad Innayatullah et al. [10] shows more of malepreponderance (50.6 \% Males Vs. 49.4 $\%$ Females).In the study conducted at Peshawar [11] had an almost equal number of males and females, however Nkrumah et al in Saudi Arabia and Khurram et al in Pakistan [12,13] noticed more females as compared to males in their studies, probably more females are being referred in the centers for endoscopy.

The age pattern is closely similar to those of other studies with very few presenting before the age of 20years, peaking in the fifth decade and a mean age of 41.45years ( $\mathrm{SD} \pm 15.343)$ probably because UGI tract diseases are prevalent in the older population age group $[6,8,14]$ and in the study by Emmanuel jeje et al [15]. The reasons for sex and age differences are due to varying sample size, geographical location and time period of study carried out.

We noticed dyspepsia in (61\%), being commonest indication for UGI Endoscopy in our study. This is similar to Malu et al (78.1\%)in their study at Zaria and so did Danbauchi et al ,Aduful et al ,Nkrumah et al ,Khurram in Pakistan, Onyekwere et al in Lagos and Cooper in USA $[7,15,16]$ Another large retrospective study from Rawalpindi ,reported lower figure of dyspepsia and higher number of GI bleed [17] .There were 10.2\% patients with chronic liver diseases included in the list of indication of OGD in that study. We excluded Hepatitis B and C positive patients .This could explain the higher number of cases with upper GI bleed in aforementioned study. A study from India [18] reported dyspepsia in 59\% of patients undergoing OGD.

In our study normal Endoscopy was reported in 40\% $(n=237)$, more common in males $29.2(n=173)$ as compared to females $10.8 \%(\mathrm{n}=64)$, which is not consistent with the result of study by Khalid Mahmud et al 
[11] , showing more female preponderance( $31.2 \%$ females Vs.28.6\% males). Rate of negative Endoscopy $(40 \%)$ in our study was less as compared to reported rates in the study of Muhhammad et al from Multan [10] and was higher as compared to negative Endoscopy $30 \%$ [11], as reported by Khalid Muhammad [11].This observation was also reportedbyShahetal[19].Strict selection criteria required to reduce this rate will result in missing significant pathology in large number of patients.

Abnormal OGD was more common in patients above 40 years as compared toGastritis was common in $25.1 \%$ in concordance with findings of Emmanuel jeje et al [15] and 31\% by Nkrumah in Saudi and 35\% obtained by Agbakwuru et al at lfe, Nigeria, which is less as compared to our study. Study from Saudi Arabia reported antral gastritis to be the commonest gastroscopy finding [20] Almost similar percentage was reported at Multan [10]This may be due to H.Pylori infection reported in patients with dyspepsia in an earlier study from Multan [21] . We based our diagnosis on gross appearance of gastric mucosa .Other important causes of dyspepsia included Esophagitis 3.5\%,which was less as compared to the study [11] which reported (11.1\%)of cases. Duodenitis was reported in $5.1 \%$ cases which was similar to the study [11] done by Khalid mahmood et al and was comparable to $27 \%$ in the study done by Emmanuel et al [15], 24.85\% by Malu and Zaria ,Nagerea and $16 \%$ by Agba Kwaru.

We reported the percentage of gastric ulcers as $6.7 \%$ who underwent OGD for dyspepsia .The overall frequency of gastric ulcer in the studied population was $6.7 \%$ as compared to duodenal ulcer which was $4 \%$ in our study, the ratio of duodenal ulcer was 0.5: 1 not in concordance with the published by Khalid Mahmood et al[11] in which overall frequency of duodenal ulcer with that of gastric ulcer was $8.1 \%$ versus $3.7 \%$.The reverse duodenal ulcer to gastric ulcer ratio was reported in our study and,was also reported from Multan [22] ,Japan and South America [23,24,25] .Gastric ulcer occurs mostly in the sixth decade in the European countries .In this study mean age was 45 years supporting the view that in India these diseases occur at an earlier age[26].

Gastric carcinoma was reported in $4.6 \%(n=27)$ similar to percentage of gastric carcinoma reported by Emmanuel jeje et al and esophageal carcinoma in $3.7 \%(\mathrm{n}=22)$, which is less as compared to Emmanuel jeje et al which is $1.7 \%$. Our findings were significantly high as compared to the percentage $(1.17 \%)$ ) as reported by Khalid Mahmood [11] and Muhammad Inayatullah et al [10] (Gastric carcinoma 2\% and esophageal carcinoma $2 \%$ ). Gastric carcinoma reported by Agbakwuru which is $11.6 \%$ was similar to the findings noted in Nigeria ,parts of Africa and other parts of the world $[6,7,8,9,10]$

The overall percentage of gastro-esophageal malignancy $(8.7 \%)$ was found in our study in patients of dyspepsia was similar to the percentage as reported by Shah et al (10\%)[19].The alarming symptoms were less clear in the studied population with a high incidence of gastro esophageal malignancy .Similar observations were noted by Sung JJ et al[27],therefore proper history and physical examination followed by selected investigations should be a rule in dyspeptic patients to confirm or exclude serious disease. The incidence of upper GI malignancy is on the rise local and in the international scenario [28, 29].

The miscellaneous pathologies were $3.5 \%$ in our study as reported by Muhammad et al [11]7\% and 14 $\%$ as reported by Shah et al [19]. Correlations of Endoscopic diagnosis and with their personal habits as obtained $\mathrm{r}=.160(\mathrm{p}=.000<.001)$ which is highly significant.

$\mathrm{H}$.pylori status and history of drug intake was not available in our study. Furthermore patients biopsy confirmation of gastro duodenal inflammation was done in small number of cases, these were the lacunae which needs rectification for the future analytic studies .Further prospective studies required to be conducted on the dyspeptic subjects so as to develop guidelines for management of dyspepsia

TABLE4:- The Correlation between Endoscopic diagnosis with personal habbits

\begin{tabular}{|l|l|l|l|}
\hline & & DIAGNOSIS & Personal Habbit \\
\hline DIAGNOSIS & Pearson Correlation & 1 & $.160(* *)$ \\
& Sig. (2-tailed) &. & .000 \\
& $\mathrm{~N}$ & 593 & 593 \\
Personal Habbit & Pearson Correlation & $.160(* *)$ & 1 \\
& Sig. (2-tailed) & .000 &. \\
& $\mathrm{~N}$ & 593 & 593 \\
\hline
\end{tabular}

** Correlation is significant at the 0.01 level (2-tailed).

\section{Conclusion}

Endoscopy is a very important investigative modality to identify the specific pathology in patients of Dyspepsia .Gastritis; Esophagitis, Duodenitis, Duodenal ulcer, Gastric ulcer, Gastric carcinomas and esophageal malignancies were as the commonest endoscopic diagnostic findings. Strict selection criteria required to reduce this rate will result in missing significant pathology in large number of patients. Correlations of Endoscopic diagnosis and with their personal habits as obtained $\mathrm{r}=.160 \quad(\mathrm{p}=.000<.001)$ which is highly significant 
TABLE-3 AGE_R

\begin{tabular}{|c|c|c|}
\hline Age Interval & Frequency & Percent \\
\hline 20 yrs to $30 \mathrm{yrs}$ & 6 & 1.0 \\
31 yrs to $40 \mathrm{yrs}$ & 36 & 6.1 \\
41 yrs to $50 \mathrm{yrs}$ & 215 & 36.3 \\
51 yrs to $60 \mathrm{yrs}$ & 161 & 27.2 \\
61 yrs to $70 \mathrm{yrs}$ & 90 & 15.2 \\
71 yrs to $80 \mathrm{yrs}$ & 85 & 14.3 \\
Total & 593 & 100.0 \\
\hline
\end{tabular}

\section{References}

[1] Heatley RV, Rathbone BJ. Dyspepsia: a dilemma for doctors? Lancet. 1987; 2(8562): 779-82.

[2] Talley NJ, Weaver AL, Tesmer DL, Zinmeister AR. Lack of discriminant value of dyspepsia subgroups in patients referred for upper endoscopy. Gastroenterology.1993; 105: 1378-86.

[3] Colin-Jones DG. The management of dyspepsia.Scandinavian Journal of Gastroenterology Supplement.1988; 155: 96-100

[4] Kasugai T. Endospicdiagnosisin gastroenterology. Tokyo: igaku-sboin 1982.

[5] Olokoba AB, Bojuwoye BJ. Indications for oesophagogastroduodenoscopy in Ilorin, Nigeria--a 30 month review. Nigerian Journal of clinical Practice. 2010; 13(3): 260-3.

[6] Agbakwuru EA, Fatusi AO, Ndububa DA et al. Pattern and validity of clinical diagnosis of upper gastrointestinal diseases in southwest Nigeria. Afr Health Sci. 2006; 6(2): 98-103.

[7] Malu AO, Wali SS, Kazmi R, Macauley D, Fakunle YM. Upper gastrointestinal endoscopy in Zaria, northern Nigeria. West African Journal of Medicine. 1990; 9(4): 279-84.

[8] Danbauchi SS, Keshinro IB, Abdu-Gusau K. Fifteen years of upper gastrointestinal endoscopy in Zaria (1978 - 1993). African journal of medicine and medical sciences. 1999; 28(1-2): 87-90.

[9] Aduful H, Naaeder S, Darko R, Baako B, Clegg-Lamptey J, Nkrumah K, et al. Upper gastrointestinal endoscopy at the korle bu teaching hospital, accra, ghana. Ghana Med J. 2007; 41(1): 12-6.

[10] Muhammad Inayatullah, Zahra Nazish Muhammad Saleem Akhtar, Abdul Hameed Anjum, Altaf Baqir Naqvi. Dyspepsia and Upper Gastrointestinal Endoscopy Professional Med J Mar 2008;15(1);143-147

[11] Khalid Mahmood, Mohammad Ilyas Saeedi, Riaz Mohammad, Zia ud Din UPPER GASTROINTESTINAL ENDOSCOPIC FINDINGS IN PATIENTS WITH DYSPEPSIA JPMI 2006 VOL.20 NO:70-73

[12] Nkrumah KN. Endoscopic evaluation of upper abdominal symptoms in adult patients, Saudi Aramco-Ai Hasa Health Center, Saudi Arabia.West African Journal of Medicine. 2002; 21(1): 1-4.

[13] Khurram M, Khaar HT, Hasan Z, Umar M, Javed S, Asghar T, et al. A 12 years audit of upper gastrointestinal endoscopic procedures.Journal of the College of Physicians and Surgeons--Pakistan: JCPSP. 2003; 13(6): 321-4

[14] Onyekwere CA, Hameed H, Anomneze EE, Chibututu C. Upper gastrointestinal endoscopy findings in Nigerians: a review of 170 cases in Lagos. The Nigerian Postgraduate Medical Journal. 2008; 15(2): 126-9.

[15] Emmanuel Jeje Thomas Olajide, Bashir Akande Upper Gastrointestinal Endoscopy - Our Findings, OurExperience in Lagoon Hospital, Lagos, Nigeria Macedonian Journal of Medical Sciences. 2013 June 1; 6(2):168-173

[16] Cooper GS. Indications and contraindications for upper gastrointestinal endoscopy. Gastrointestinal Endoscopy Clinics of North America. 1994; 4(3): 439-54.

[17] Khurram M, Kharr HB, Hasan Z, Umar M,Javed S, Asghar T et al. A 12 years audit of upper gastrointestinal endoscopic procedures. J Coll Physicians Surg Pak 2003; 13: 321-4.

[18] Katelaris OH, Tippet GH, Norbu P, Lowe DG,Br e n n a n R, F a t h i n g MJ Dyspepsia, Helicobacter pylori and peptic ulcer in a randomly selected population in India. Gut 1992; 33: 1462-6.

[19] Shah NH, Shah MS, Khan I, Hameed K An audit of diagnostic upper GI endoscopic and comparison of booked vesus open access cases JCPSP 1999;9(4);174

[20] Rabbani A. Experience with Endoscopy at Bin Jalawi Hospital K.S.A.J Ayub Med Coll Abottabad 2005;17:37-9

[21] Inayatullah M Arshad M Nasir SA et al. Occurrence of Helicobactor pylori in patients presenting with dyspepsia. Pak J of gastroenterology 1993; 7 (1);74

[22] Zafar MH, Nasir SA, Anjum AH , et al. Acid peptic disease in Multan region. Pak J of gastroenterology 1986;1 (1);14

[23] Coggon D, Lambert P, Lagman MJS, 20 years of hospital administration for peptic ulceri England and Wales. Lancet 1981;1;1;1302

[24] Schoon MI, Melstrom D,Oden A, Ytterberg B. Incidence of peptic ulcer disease in Gothemberg. BMJ 1989;1131

[25] Welsh JD, Wolf SR, Geographical and environmental aspects of peptic ulce. Am J Med 1960;29;754.

[26] Ziauddin. Endoscopic findings in dyspepsia-A prospective study of 200 cases. J Postgrad Med Inst 2003; 17: 235-9.

[27] Sung JJ, Lao WC, Lai MS, Li TH, Chan FK, Wu JC, et al. Incidence of gastroesophageal malignancy in patients with dyspepsia in Hong Kong: Implications for screening strategies. Gastrointest Endosc 2001; 54:454.

[28] Sp e c h l e r SJ. Ba r r e t t ' s e s o p h a g u s a n d esophageal adenocarcinoma: Pathogenesis, diagnosis, and therapy. Med Clin North Am 2002; 86:1423-45

[29] Shah NH, Shah MS, Khan I, Hameed K. Dyspepsia in Afghan Refugees - Do prompt endoscopy. J Ayub Med Coll Abottabad 1999; 11: 51-3. 